\title{
Adsorption of Heavy Metal from Palm Oil Mill Effluent on the Mixed Media Used For the Preparation of Composite Adsorbent
}

\author{
Adeleke Abdulrahman Oyekanmi ${ }^{1,2, *}$, Ab Aziz Abdul Latiff ${ }^{1,2}$, Zawawi Daud ${ }^{1,2}$, NurFalilah \\ Mat Daud ${ }^{1}$, and Paran Gani ${ }^{1}$ \\ ${ }^{1}$ Department of Water and Environmental Engineering, Faculty of Civil and Environmental \\ Engineering, Universiti Tun Hussein Onn Malaysia, 86400, Parit Raja Batu Pahat, Johor, Malaysia \\ ${ }^{2}$ Team of Researchers in Integrated Solid Waste Management (TRISM). Faculty of Civil and \\ Environmental Engineering, Universiti Tun Hussein Onn Malaysia, 86400, Parit Raja Batu Pahat, \\ Johor, Malaysia
}

\begin{abstract}
The adsorption of lead ion from palm oil mill effluent produced directly from the mill was investigated using mixed adsorbents that were used to prepare the composite. Experiments were carried out under predetermined conditions of $\mathrm{pH}$, shaking speed, contact time and particle size. Equilibrium study was carried out to determine the adsorption capacity of the mixed media. The reduction of the lead ion was effective on the adsorbent materials. The Temkin and Freundlich models were applied to describe the adsorption pattern on the mixed media. The experimental data fitted well to the Temkin isotherm with a correlation coefficient of 1 , this was used to indicate the level of interaction of the adsorbent-adsorbate and also the energy utilized in the adsorption process. The hydrophobic behaviour of the activated coconutshell and cow bone carbons was observed for average contact angle of $105^{\circ}$ and $95^{\circ}$ for the coconut shell and cow bone respectively. The influence of the hydrophobic materials in the mixed media and the zeolite assisted in the ion exchange and in the adsorption of the heavy metal.
\end{abstract}

\section{Introduction}

Palm oil mill effluent (POME) is well known as a very high strengthwastewater. The discharge of POME from the processing mill without effective treatment may result to the deterioration of water bodies, other sources of waste containing pollutants are from domestic, urban and other industrial sectors [1]. Some of the pollutants include chemicals, sewage, fertilizer, pesticide and heavy metals. The presence of these pollutants in the aquatic ecosystem has severe damaging effect on the health of the environment, human and the aquatic habitat [2].

Heavy metal in water source isa big challenge threatening the ecosystem for researchers. The presence of heavy metals causes health disorder [3]. Several methods have

*Correspondingauthor: abdulkan2000@yahoo.com 
been reported for the removal of heavy metals of POME from water bodies. POME is the major wastewater in many Asian countries such as Malaysia and Indonesia but the treatment of the effluent mostly has been reported using conventional means. Some of these methods are ion exchange, chemical precipitation, membrane filtration and photocatalysis.Adsorption offers economic benefits interms of cost, efficiency interms of treatment, and produces high quality effluents better than other conventional methods. Also, adsorption materials have great potentials of regeneration by desorption process. The process of regeneration requires low maintenance cost, high treatment efficiency and ease of operation [4]. Adsorption study is widely conducted using single material in the past, such as the use of cow bones [5], banana peel [6], maize cob [7], peat [8], kaoline [9] etc.Due to the high strength nature of POME, previous researches on adsorption have been conducted as the secondary treatment after majortreatment from the aerobic pond or before discharge. [10-12].

In recent study of adsorption, adsorbent materials are identified on the basis of their efficiency; usually two or more materials are combined with suitable binder to develop a new composite adsorbentto enhance adsorption. In the present work, batch adsorption of lead was investigated as primary treatment of POME using the mixed media that was used in the preparation of the composite. The materials were activated cowbone powder, activated coconut shell carbon and zeolite. The ordinary Portland cement (OPC) was used as binder because of its good pozolonic properties. The objective was to investigate the effectiveness of the mixed media for the reduction of lead ion in raw palm oil mill effluent (POME).

\section{Materials and Method}

\subsection{Preparation of the Adsorbent Materials}

The locally sourced materials for the preparation of composite were selected on the basis of their hydrophobic and hydrophilic behaviour in fluid. This is to classify materials on the basis of the effectiveness to adsorb polar and non-polar pollutants in the adsorbate. The process is usuallydetermined by the contact angle measurement. The materials chosen for this work were coconut shell carbon, cow bone carbon and zeolite. The coconut shells were obtained from the factory of Kian Hoe Johor, Malaysia.

The materials were washed thoroughly, dried and crushed. A predetermined weight of $500 \mathrm{~g}$ of the dried sample of coconut shellwas obtained at $110^{\circ} \mathrm{C}$ for $2 \mathrm{~h}$. The carbonization of the crushed sample was obtained at $250^{\circ} \mathrm{C}$ to form char, this was followed by activation process at $850^{\circ} \mathrm{C}$ for $2 \mathrm{~h}$ under the flow of $\mathrm{CO}_{2}$, and this was achieved at heating rate of $5^{\circ} \mathrm{C}$. The bulk density of $0.57 \mathrm{~g} / \mathrm{ml}$ was obtained and used for the composite. Fresh cow bones were obtained in the local market in Parit Raja Johor. The method of preparation and characterization of the activated cow bone having bulk density measured at $0.63 \mathrm{~g} / \mathrm{ml}$ was in our previous work [13]. Also, the natural zeolite used for this work was from Clinoptiloliteorigin has the bulk density of $0.97 \mathrm{~g} / \mathrm{ml}$, the materialwas purchased at $3.7 \mathrm{RM} / \mathrm{Kg}$ from local suppliers. The bulk densities of the starting materials were obtained using the method in[14]. Also, the OPC provided the binding effect at different adsorbent:OPC binding ratios. The materials were thoroughly mixed together using a mechanical mixer and the particle size of $150 \mu \mathrm{m}$ was used for the bulk densities used present study, this was obtained using the ceramic ball grinder. The adsorbent: OPC ratio used is presented in Table 1.

The surface morphology of the mixed materials (adsorbent:OPC) was achieved using the scanning electron microscopy at 500x magnification. Prior to the investigation, adsorbent material was plated with gold. The bulk density of the adsorbent: OPC used was $0.768 \mathrm{~g} / \mathrm{ml}$. The elemental composition of the mixed media was obtained using the energy 
dispersive x-ray spectroscopy (EDX INCA-Oxford High Wycombe, UK). The result is presented in Table 2 .

\subsection{Adsorption Experiment}

The sorption capacity of the composite was determined by the surface contact of the different mixed ratios of the contributing materialsin Table 1, the materials combined were selected from the contact angle measurement in Fig.1.The combined materials were obtained from the bulk densities of the prepared adsorbents. The surface characterization of mixed media is illustrated in Fig.2.

Table 1. Adsorbent: OPC ratio

\begin{tabular}{|l|l|l|l|l|l|l|l|l|l|}
\hline \% Adsorbent & 90 & 80 & 70 & 60 & 50 & 40 & 30 & 20 & 10 \\
\hline Adsorbent(g) & 21.79 & 19.37 & 16.944 & 14.524 & 12.103 & 9.682 & 7.262 & 4.841 & 2.4206 \\
\hline CBP & 5.106 & 4.54 & 3.97 & 3.404 & 2.8365 & 2.2692 & 1.7021 & 1.135 & 0.5673 \\
& & & & & & & & & \\
\hline CAC & 8.511 & 7.57 & 6.62 & 5.674 & 4.7275 & 3.7820 & 2.8369 & 1.189 & 0.9456 \\
& & & & & & & & & \\
\hline ZEO & 8.171 & 7.27 & 6.354 & 5.447 & 4.5386 & 3.6308 & 2.723 & 1.8154 & 1.5129 \\
\hline \% Binder & 10 & 20 & 30 & 40 & 50 & 60 & 70 & 80 & 90 \\
\hline Binder (g) & 0.5 & 1.0 & 1.5 & 2.0 & 2.5 & 3.0 & 3.5 & 4.0 & 4.5 \\
\hline
\end{tabular}

The batch study was conducted using $250 \mathrm{ml}$ Erlenmeyer flasks at fixed condition of $150 \mathrm{rpm}$ shaking speed, 105 minutes contact time and at neutral $\mathrm{pH}$ condition. The adjustmentof the $\mathrm{pH}$ was done using $0.1 \mathrm{M} \mathrm{HCl}$ and $0.1 \mathrm{M} \mathrm{NaOH}$. After the completion of each contact time, filtration using $0.45 \mu \mathrm{m}$ membrane was conducted to separate the adsorbate from the solutions. The filtered samples were analysed using the inductively coupled plasma mass spectrometer ICP-MS ELAN 9000. All experiments were conducted in triplicate. The equilibrium liquid phase concentration was calculated as:

$$
\mathrm{Q}_{\mathrm{e}}=\frac{\mathrm{C}_{\mathrm{o}}-\mathrm{C}_{\mathrm{e}}}{W} v
$$

whereQ $\mathrm{Q}_{\mathrm{e}}$ is the equilibriumuptake $(\mathrm{mg} / \mathrm{g}), \mathrm{V}$ is the volume of solution $(\mathrm{L}), \mathrm{C}_{\mathrm{o}}$ is the initial concentration of lead $(\mathrm{mg} / \mathrm{L}), \mathrm{C}_{\mathrm{e}}$ is the final concentration of lead $(\mathrm{mg} / \mathrm{L})$.

\subsection{Adsorbent Experiment}

In this study, two adsorption isotherms were adopted, the Freundlich isotherm to investigate the heterogeneity of the surface of the adsorbent on the adsorbate and the Temkin isotherm, to express the adsorbent-adsorbate relationship and the heat energy used in the adsorption process.

\section{Results and Discussion}

The adsorption of lead was conducted on mixed materials used to prepare the composite adsorbent. The materials selected were of hydrophobic and hydrophilic characteristics in the adsorbate. The measurement of the contact angles of these materials using water drop 
can be shown in Fig. 1. An adsorbent material is hydrophobic if the contact angle is greater than $90^{\circ}$ [15]. It is highly hydrophobic if is greater than $120^{\circ}$ [16]. Also when a material has contact angle less than $90^{\circ}$, it is considered as hydrophilic [17].
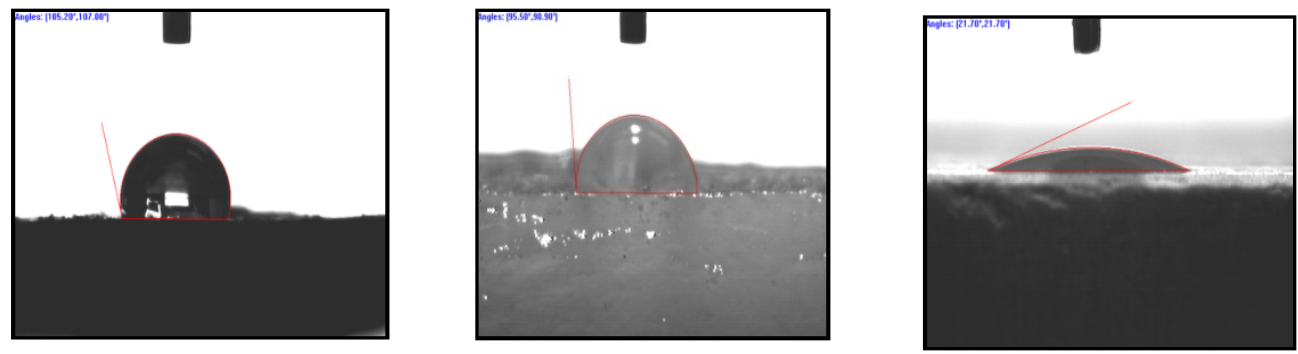

Fig.1.Contact angle $105^{\circ}, 95^{\circ}, 21^{\circ}$ for coconut shell, cowbone and zeolite respectively.

The surface morphology was obtained at $20.0 \mathrm{kv}$ using a magnification image of $500 \mathrm{x}$, the image analysis was done simultaneously with EDX analysis in Table 2. The surface characterization is shown in Fig. 2. The microstructure of the prepared media appears smooth except in cases of cracks and holes experienced on some surfaces. The percentage of carbon in the mixed material was reasonably high, this may be as a result of the presence of the hydrophobic coconut shell and cow bones. The presence of carbon on the available sites for sorption provided the attachment of the lead metal on the mixed media.

The adsorption of lead on the mixed media was conducted on fresh samples of POME for primary treatment. The adsorptionstudywas conducted at different adsorbent: binder ratio in Table 1.

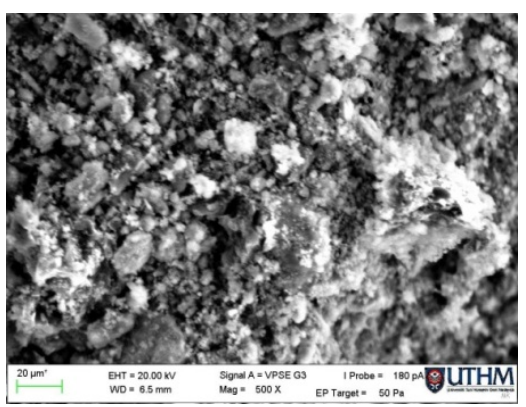

Fig.2. Surface Characterization of adsorbent

The concentration of the metal uptake was obtained after the completion of each shaking time and filtration process of the treated samples using 0.45 micro filter membranes. The batch isotherm study on the experimental data showed that the model fitted better to the Temkin isotherm with a correlation coefficient $\left(\mathrm{R}^{2}\right)$ of 1.00 , the Temkin constants of BT served as the expression of slope and KT $(\mathrm{L} / \mathrm{g})$ as the expression of the intercept. The value of BT was 2570 and KT was $1.4527 \mathrm{~L} / \mathrm{g}$. The Temkin isotherm showed that the adsorption of lead ion decreases linearly on the adsorbate due to the adsorbentadsorbate interactions. 
Table 2. Elemental composition of the mixed Adsorbent.

\begin{tabular}{llc}
\hline Element & Mass\% & $\mathrm{At} \%$ \\
\hline $\mathrm{C}_{\mathrm{k}}$ & 28.62 & 39.52 \\
$\mathrm{O}_{\mathrm{k}}$ & 48.39 & 50.15 \\
$\mathrm{Na}_{\mathrm{k}}$ & 1.56 & 1.12 \\
$\mathrm{Mg}_{\mathrm{k}}$ & 1.07 & 0.73 \\
$\mathrm{P}_{\mathrm{k}}$ & 2.14 & 1.15 \\
$\mathrm{Ca}_{\mathrm{k}}$ & 16.85 & 6.97 \\
$\mathrm{Cu}_{\mathrm{k}}$ & 1.38 & 0.37 \\
\hline Total & & 100.00 \\
\hline
\end{tabular}

The Temkin constant (BT) describes the variation of the adsorption energy, the model is based on the principle that the decrease of the heat energy of adsorption tends to be linear than logarithmic [18]. If adsorption of BT $>1$, the adsorption process is exothermic, also the adsorption process is endothermic if BT $<1$.In this study, the value of BT exhibited an exothermic behaviour of the process of adsorption[19]. This suggests that there is an electrostatic interaction and the heterogenous pore spaces of the coconut shell activated carbon and the cow bone activated carbon played a very significant role. The Freundlich isotherm is widely used to describe the adsorption process on heterogeneous surface. The Freundlich model showed $\mathrm{R}^{2}$ of 0.9828 , the slope $1 / \mathrm{n}$ was 0.71598 and intercept $\mathrm{K}_{\mathrm{F}}$ of 0.4514 was acheived. The slope $1 / \mathrm{n}$ describes the surface heterogeneity or the adsorption intensity and $\mathrm{K}_{\mathrm{F}}$ shows the adsorption capacity. The value of $1 / \mathrm{n}$ is known to be in the range of 0 to 1 . A value closer to zero indicates favourable adsorption and a heterogeneous surface. From the slope of the Freundlich isotherm, it can be said that the mixed media have high heterogeneous surface in terms of the slope of the isotherm. The adsorption process was noticeably high at a higher ratio of adsorbent to minimal OPC application, this was due to the difference in the concentration between the bulk solution and the solid-liquid interface. The zeolite in the composite provided the adsorption sites and enhanced the interaction of the lead ion with the sites[20]. The result of the adsorption isotherm study is presented in Fig. 3 and 4:

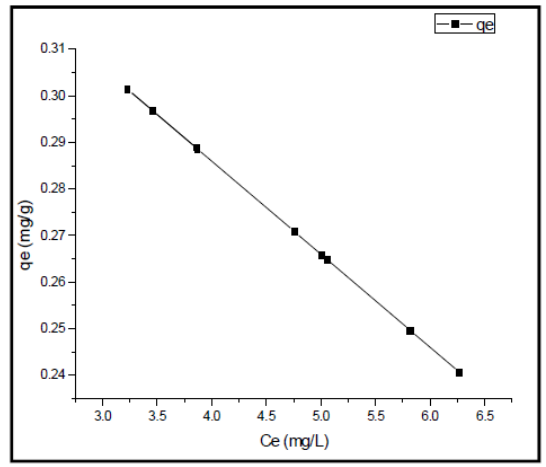

Fig.3. the Temkin Isotherm

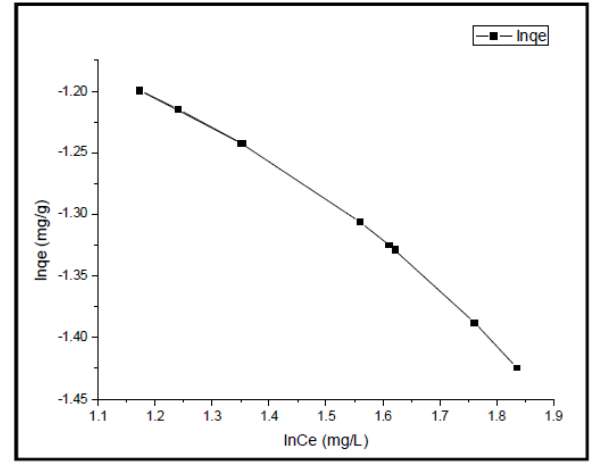

Fig.4. Freundlich Isotherm 


\section{Conclusions}

The materials used for the preparation of the composite adsorbent in this work showed effective reduction of lead ion from POME. The result indicated that high carbon content of the adsorbent, the hydrophobic behaviour of the coconut shell activated carbon and cow bone carbon favoured the attachment of the metal ion on the surface of the sorbent. The isotherm model fitted better to the Temkin model. This was used to determine the extent of the adsorbent-adsorbate interaction and the energy involved in the adsorption process. The adsorbent materials showed great potential for a new composite adsorbent which can be well suited for the effective reduction of heavy metals in other high strength wastewater.

This research was supported by Universiti Tun Hussein Onn Malaysia (UTHM), Malaysia, The Ministry of Higher Education Malaysia through Fundamental Research Grant Scheme (FRGS), Vot. 1571.

\section{References}

[1] N. N. N. Daud and A. A. Syazwani. Preliminary assessment of lakes water quality status at campus area in selangor, malaysia,131, 279-292,(2016)

[2] K. Iwahori, J. I.Watanabe, Y.Tani, H, Seyama and N.Miyata. Removal of heavy metal cations by biogenic magnetite nanoparticles produced in Fe (III)-reducing microbial enrichment cultures. J. of bioscience and bioengineering, 117(3), 333-335, (2014).

[3] M. Matouq, N. Jildeh, M. Qtaishat, M. Hindiyeh and M. Q. Al Syouf. The adsorption kinetics and modeling for heavy metals removal from wastewater by Moringa pods. J. of Environmental Chemical Engineering, 3(2), 775-784. (2015).

[4] M. Kobya, E. Demirbas, and F. Ulu. Evaluation of operating parameters with respect to charge loading on the removal efficiency of arsenic from potable water by electrocoagulation. J. of Environmental Chemical Engineering, 4(2), 1484-1494, (2016).

[5] A. R. O Adeleke, A. A.L. Aziz, Z. Daud, B. Ridzuan, M. Daud and N. Falilah, Remediation of raw wastewater of palm oil mill using activated cow bone powder through batch adsorption. In Key Engineering Materials, 705, 380-384, (2016).

[6] J. Anwar, U. Sfafique, M. Salman, A. Dar and S. Anwar. Removal of Pb (II) and Cd (II) from water by absorption on peels of banana, Bioresource Technology, 10(6), 1752-1755, (2010).

[7] K. Y. Foo,Value-added utilization of maize cobs waste as an environmental friendly solution for the innovative treatment of carbofuran, Process Safety and Environmental Protection, 100, 295-304, (2016).

[8] H. I. Chieng, L. B.Lim, and N. Priyantha, Sorption characteristics of peat from Brunei Darussalam for the removal of rhodamine B dye from aqueous solution: adsorption isotherms, thermodynamics, kinetics and regeneration studies, Desalination and Water Treatment, 55(3), 664-677, (2015).

[9] E. I. Unuabonah, B. I. Olu-Owolabi and K. O. Adebowale. Competitive adsorption of metal ions onto goethite-humic acid-modified kaolinite clay. Int. J. of Environmental Science and Technology, 13(4), 1043-1054, (2016).

[10]R.R. Mohammed and M.F. Chong. Treatment and decolorization of biologically treated palm oil mill effluent (POME) using banana peel as novel biosorbent. J. of Env.Management.132, 237-249, (2014). 
[11]A.L., Ahmad, S. Sumathi and B.H. Hameed, Adsorption of residual oil from palm oil mill effluent using powder and flake chitosan: Equilibrium and kinetic studies. Water Research, 39(12), 2483-2494, (2005).

[12] M.A. Shavendi, Z, Haddadian, M.H.S Ismail, N., Abdullahi and Z.Z. Abidin, Removal of Fe(III), Mn (III) and Zn (II) from Palm Oil Mill Effluent (POME) by natural zeolite. J. of the Taiwan Institute of Chemical Engineers, 43(5), 750-759, (2012).

[13]A. Latiff, A.Aziz, O. Adeleke AbdulRahman, Z. Daud, M. B. Ridzuan, M. Daud, and N. Falilah, Batch adsorption of manganese from palm oil mill effluent onto activated cow bone powder, ARPN J. of Engineering and Applied Science, 11(4), 2627-2631, (2015).

[14]C. H. Chia, A. Downie, and P.Munroe, Characteristics of biochar: physical and structural properties, Biochar for environmental management: science and technology, Earthscan Books Ltd, London, 89-109, (2015).

[15]T. Monroe, S. Bhaduri, A.Koch and K. Lant, Making Clays Water Resistant: New Technology That Minimizes Formation Damage. In SPE European Formation Damage Conference and Exhibition, Society of Petroleum Engineers, (2015).

[16]M. R, Hibbs, L. K. McGrath, S. Kang, A. Adout, S. J. Altman, M. Elimelech and C. J. Cornelius, Designing a biocidal reverse osmosis membrane coating: Synthesis and biofouling properties, Desalination, 380, 52-59, (2016).

[17]J. Zhao, H. Lai, Z. Lyu, Y. Jiang, K. Xie, X. Wang and J. Liu. Hydrophilic Hierarchical Nitrogen-Doped Carbon Nanocages for Ultrahigh Supercapacitive Performance, Advanced materials, 27(23), 3541-3545, (2015).

[18]X.j., Hu, J.S., Wang., Y.G., Liu, G.M., Zeng, Z.I., Bao. A. W. X-Zeng and F. L. Chen. Adsorption of chromium (VI) by ethylene diamine modified cross linked magnetic chitosan resin, Isotherm, kinetics and thermodynamics, J. of Harzardous material, 185, 306-314, (2011).

[19]A. C. Martins, O. Pezoti, A. L. Cazetta, K. C. Bedin, D. A.Yamazaki, G. F. Bandoch and V. C.Almeida. Removal of tetracycline by $\mathrm{NaOH}$-activated carbon produced from macadamia nutshells: Kinetic and equilibrium studies, Chemical Engineering J., 260, 291-299, (2015).

[20]T. Motsi, N.A., Rowson and M.J.H. Simmons, Adsorption of heavy metals from acid mine drainage by naturalzeolite, Int.J. of Mineral Processing, 92, 42-48, (2009). 